\title{
Perencanaan Perawatan pada Mesin Cake Breaker Conveyor di Pabrik Kelapa Sawit
}

\section{Maintenance Planning on Cake Breaker Conveyor Machine in Palm Oil Mill}

\author{
Muhammad Ihsan Hamdy*, Yanti Sopianti, Ekie Gilang Permata, Muhammad Nur \\ Program Studi Teknik Industri, Fakultas Sains dan Teknologi \\ Univeristas Islam Negeri Sultan Syarif Kasim Riau \\ Jl. HR. Soebrantas No. 155 Simpang Baru, Panam, Pekanbaru, 28293, Indonesia \\ E-mail: m.ihsanhamdy@uin-suska.ac.id,ysoviany@gmail.com,ekiegp@yahoo.com \\ muhammadnur@uin-suska.ac.id
}

\begin{abstract}
ABSTRAK
Penelitian ini dilakukan pada sebuah perusahaan pengolahan kelapa sawit. Permasalahan pada studi ini adalah adanya kerusakan mesin dan belum menemukan solusi hingga saat ini. Reliability Centered Maintenance adalah salah satu metode untuk menentukan tindakan pemeliharaan pada komponen kritis. fokus kajian ini pada mesin Cake Breaker Conveyor (CBC) berdasarkan hasil analisis menggunakan FMEA method (Failure Mode and Effect Analisys). hasilnya diperolah bahwa nilai RPN tertinggi diperoleh pada 4 komponen kritis dari 11 komponen utama mesin Cake Breaker Conveyor (CBC) yaitu komponen bearing, Universal Joint, Batang Kopling dan Pen. lebih lanjut, dilakukan penentuan jadwal perawatan komponen kritis pada stasiun ini. Kerusakan Bearing, distribusi Lognormal, dijadwalkan pergantian 461,5 (Jam). untuk Kerusakan Pen, distribusi Normal, dilakukan penjadwalan pergantian 587,29 (Jam). Kerusakan Universal Joint, distribusi Normal, Usulan Jadwal Pergantian 536,46 (Jam), Kerusakan Batang Kopling, distribusi Normal, Usulan Jadwal Pergantian 581,6 (Jam), dan kerusakan As, distribusi Normal, Usulan Jadwal Pergantian 586,6 (Jam).
\end{abstract}

Kata Kunci: Reliability Centered Maintanance, FMEA, Perawatan, Kelalapa sawit.

\section{ABSTRACT}

This research was conducted at a palm oil processing industry. The problem in this study is the engine failure and have not found a solution to date. Reliability Centered Maintenance is one method for determining maintenance actions on critical components. The focus of this study is on the Cake Breaker Conveyor $(C B C)$ machine based on the results of the analysis using the FMEA method (Failure Mode and Effect Analysis). the result was found that the highest RPN value was obtained on 4 critical components from 11 main components of the Cake Breaker Conveyor (CBC) machine namely bearing components, Universal Joint, Clutch Rod and Pen. furthermore, a critical component maintenance schedule at this station was determined. Bearing failure, Lognormal distribution, scheduled change of 461.5 (Hours). for Pen Damage, Normal distribution, 587.29 (Hours) turnover is scheduled. Universal Joint Damage, Normal distribution, Proposed Replacement Schedule 536.46 (Hours), Clutch Bar Damage, Normal distribution, Proposed Replacement Schedule 581.6 (Hours), and As damage, Normal distribution, Proposed Replacement Schedule 586.6 (Hours) .

Keywords: Reliability Centered Maintanance, FMEA, Maintenance, Palm oil.

\section{Pendahuluan}

Perawatan (maintenance) berperan penting dalam kegiatan produksi dari suatu perusahaan yang menyangkut kelancaran dan kemacetan produksi, volume produksi, serta produk agar produksi dan diterima konsumen tepat pada waktunya dan menjaga agar tidak terdapat sumber daya yang menganggur karena kerusakan (breakdown) pada mesin sewaktu proses produksi sehingga dapat meminimalkan biaya kehilangan produksi atau bila mungkin biaya tersebut dapat dihilangkan. Selain itu perawatan yang baik akan meningkatkan kinerja 
perusahaan, nilai investasi yang dialokasikan untuk peralatan dan mesin dapat diminimasi, dan pemeliharan yang baik juga dapat meningkatkan kualitas produk yang dihasilkan dan mengurangi waste (Sitepu dan Hermawan, 2018).

Salah satu industri manufaktur yang bergerak dibidang pengolahan kelapa sawit sering mengalami permasalahan breakdown mesin yang tinggi. Ketika melakukan observasi diikuti kegiatan wawancara kepada kepala bagian pengolahan kelapa sawit dan maintenance, diketahui bahwa terdapat 1 mesin yang memberikan kontribusi downtime terbesar yaitu mesin Cake Breaker Conveyor. Pada mesin Cake Breaker Conveyor berubahnya setelan mesin beserta ausnya kondisi komponen lainnya membuat putaran tidak seimbang sehingga getaran semakin kuat, hal ini mengakibatkan terjadinya kerusakan pada komponen mesin. Semakin lama waktu perbaikan atau penggantian komponen mesin produksi maka semakin lama pula proses produksi terhenti yang akan berpengaruh pada kelancaran produksi.

Kapasitas pengolahan adalah 45 ton TBS/jam, sehingga apabila tidak terjadi kerusakan mesin yang menyebabkan downtime maka pabrik akan dapat meningkatkan pengolahan tandan buah segar (TBS) dan kapasitas pengolahan akan meningkat. Proses produksi yang berhenti karena kerusakan mesin menyebabkan rendahnya kapasitas pengolahan pabrik.

Adapun tujuan penelitian dari penelitian ini adalah: Menentukan jadwal perawatan komponen kritis pada stasiun pemisah biji dan rekomendasi jenis tindakan/aktivitas perawatan yang dilakukan pada setiap komponen kritis yang diteliti.

\section{Metode Penelitian}

\section{Objek Penelitian}

Objek penelitian adalah mesin Cake Breaker Conveyor (CBC) yang digunakan dalam bidang pengolahan kelapa sawit.

\section{Jenis Data}

Data primer yaitu terdiri dari data kerusakan mesin, data breakdown mesin, data lama waktu perbaikan, data waktu kerusakan.

\section{Pengolahan Data}

Pengolahan data yang dilakukan dalam penelitian ini dijabarkan sebagai berikut:

\section{Tahapan RCM}

1. Memilih sistem dan melakukan pengamatan terhadap cara kerja sistem terpilih untuk pengumpulan informasi.

2. Mendefinisikan batasan sistem

3. Mendeskripsikan sistem secara detail dengan Functional Block Diagram (FBD).

4. Mengidentifikasi fungsi sistem dan kegagalan fungsi.

5. Melakukan Failure Mode \& Effect Analysis (FMEA).

6. Pemilihan tindakan.

7. Penetapan penjadwalan penggantian komponen kritis

8. Menentukan pola distribusi

\section{Hasil dan Pembahasan}

\section{Pemilihan Sistem dan Pengumpulan Informasi}

Stasiun-stasiun pengolahan kelapa sawit bekerja secara berurutan mulai dari proses awal hingga akhir (gambar 1). Sehingga dengan meminimalkan kerusakan pada mesin dengan kerusakan tertinggi akan dapat menurunkan breakdown secara keseluruhan.

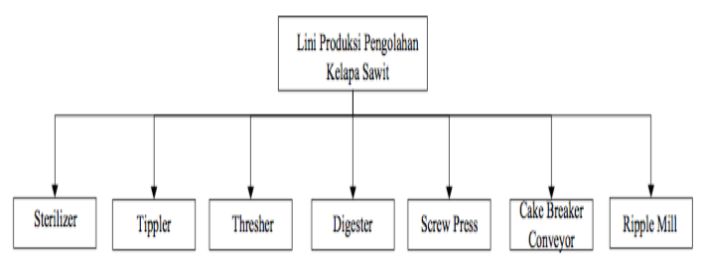

Gambar 1. Struktur Hirarki Proses Produksi Pengolahan Kelapa Sawit (Sumber : Pengolahan Data, 2020)

\section{Definisikan Batasan Sistem}

Jumlah sistem yang mendukung suatu fasilitas sangat bervariasi tergantung pada kompleksitas fasilitas itu sendiri. Dalam proses analisis RCM, definisi batasan sistem sangat penting karena:

1) Dapat membedakan secara jelas antara sistem yang satu dengan yang lainnya dan dapat membuat daftar komponen yang mendukung sistem tersebut. Hal ini dapat mencegah terjadinya tumpang tindih atau overlapping.

2) Dapat mendefinisikan sistem input output dari sistem. Dengan adanya 
perbedaan yang jelas antara apa yang masuk dan keluar dari suatu sistem maka akan sangat membantu dalam akurasi analisis proses RCM pada langkah berikutnya

3) Definisi batasan sistem terdiri dari peralatan mayor (mayor equipment) dan batasan fisik (physical primer boundaries).

\section{Penjelasan Sistem dan Functional Block Diagram}

Suatu sistem dapat dideskripsikan berdasarkan fungsi dari subsistemnya. Fungsi dari stasiun pemisah biji adalah memisahkan antara ampas (fibre) dan biji (nut) serta menampung sementara biji sebelum dilakukan proses selanjutnya. Gambar 2 dibawah ini menunjukkan functional block diagram fungsi subsistem stasiun pemisah biji. Selain itu, input dan output sistem tersebut juga digambarkan untuk menyatakan apa yang menjadi masukan dan keluaran dari setiap subsistem tersebut.

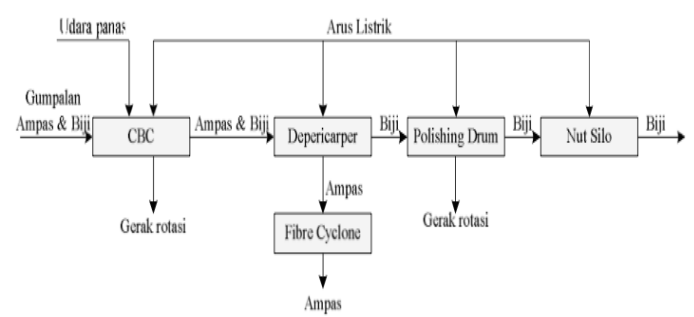

Gambar 2. Functional Block Diagram (Sumber : Pengolahan Data, 2020)

\section{Fungsi Sistem dan Kegagalan Fungsi}

Tabel 1. Fungsi dan Kegagalan Fungsi Subsistem

\begin{tabular}{|c|l|l|}
\hline No. Fungsi & $\begin{array}{l}\text { No. } \\
\text { Kegagalan } \\
\text { Fungsi }\end{array}$ & Uraian Fungsi/Kegagalan Fungsi \\
\hline \multicolumn{3}{|c|}{ 1. Sub Sistem Cake Breaker Conveyor } \\
\hline 1.1 & & $\begin{array}{l}\text { Membawa/menghantar ampas } \\
\text { dan biji }\end{array}$ \\
\hline & 1.1 .1 & Keausan pada komponen \\
\hline & 1.1 .2 & Gagal melakukan rotator \\
\hline
\end{tabular}

\section{Identifikasi Komponen Kritis}

Penentuan komponen Kritis pada penelitian ini menggunakan metode pendekatan secara langsung dan menggunakan tools Tabel Failure Mode and Effect Analysis (FMEA).

Digunakan untuk mengidentifikasi Functions, Functional Failures, Failure Modes, Failure Effect, serta menghitung nilai RPN (Risk PriorityNumber).
$\mathrm{RPN}=\mathrm{S} \times \mathrm{O} \times \mathrm{D}$

Keterangan: $\mathrm{S}=$ Severity $\mathrm{O}=$ Occurance $\mathrm{D}=$ Detection

Tabel 2. Identifikasi Komponen Kritis Pada Mesin CBC

\begin{tabular}{|c|c|}
\hline No & $\begin{array}{c}\text { Pertanyaan dan } \\
\text { jawaban }\end{array}$ \\
\hline \multirow[t]{2}{*}{1} & Apa saja komponen utama mesin $\mathrm{CBC}$ ? \\
\hline & $\begin{array}{l}\text {-Electromotor } \\
\text {-Gear box } \\
\text {-kopling } \\
\text {-Pedal/ Screw Conveyor } \\
\text {-Pipa } \\
\text {-as } \\
\text {-Pen }\end{array}$ \\
\hline \multirow[t]{2}{*}{2} & Apa saja komponen kritis dari mesin CBC? \\
\hline & $\begin{array}{l}\text {-Bearing CBC } \\
\text {-Universal Joint } \\
\text {-Pen } \\
\text {-Batang Kopling }\end{array}$ \\
\hline \multirow[t]{2}{*}{3} & Apa saja Penyeba kerusakan Bearing? \\
\hline & $\begin{array}{l}\text {-Pemasangan tidak sesuai } \\
\text {-Korosi } \\
\text {-Toleransi antar shaft dan Bearing tidak sesuai } \\
\text {-Perawatan tidak tepat }\end{array}$ \\
\hline \multirow[t]{2}{*}{4} & Apa saja mode kegagalan Universal Joint? \\
\hline & $\begin{array}{l}\text {-Universal Joint patah } \\
\text {-Umur pakai berkurang }\end{array}$ \\
\hline \multirow[t]{2}{*}{5} & Apa saja Penyebab kerusakan Universal Joint? \\
\hline & $\begin{array}{l}\text {-korosi } \\
\text {-Overload } \\
\text {-Pemasangan tidak tepat }\end{array}$ \\
\hline \multirow[t]{2}{*}{6} & Apa saja mode kegagalan Pen? \\
\hline & -Pen patah \\
\hline \multirow[t]{2}{*}{7} & Apa saja Penyeabab Pen patah? \\
\hline & $\begin{array}{l}\text {-Korosi } \\
\text {-Overload }\end{array}$ \\
\hline \multirow[t]{2}{*}{8} & Apa saja mode kegagalan batang kopling? \\
\hline & -Batang kopling Patah \\
\hline \multirow[t]{2}{*}{9} & Apa saja Penyebab batang kopling patah? \\
\hline & -Korosi \\
\hline
\end{tabular}

Penentuan komponen kritis seacara langsung tidak terlalu memeberikan informasi Mengenai Mesin CBC Sehingga diperlukan proses menilai tingkat keseriusan dari efek yang ditimbulkan (severity), keseringan terjadi kegagalan (occurance) dan Pengendali kegagalan (detection). Proses FMEA digunakan pada masalah ini untuk mengidentifikasi kesalahan atau kegagalan dalam proses manufaktur karena FMEA digunakan sebagai alat perencanaan untuk mengidentifikasi dan mengeliminasi potensi kegagalan atau kerusakan.

Tabel 3 menunjukkan nilai RPN dari komponen kritis. Terdapat 4 komponen kritis dengan nilai RPN paling tinggi yaitu komponen Bearing dengan nilai RPN 560, angka tersebut didapat dari nilai severity 8 yang artinya berada pada tingkat sangat tinggi, karena dapat menyebabkan gangguan pada lini produksi, misalnya ketika proses produksi sedang berjalan, dan tiba-tiba komponen bearing mengalami kerusakan maka proses produksi pada mesin Cake Breaker Conveyor akan terhenti sehingga hal 
tersebut dapat merugikan pihak perusahaan, $100 \%$ produk harus dibongkar, produk tidak dapat dioperasikan dan kehilangan fungsi utamanya yaitu mengurangi gesekan antara poros dan elemen mesin lainya, untuk nilai occurance sebesar 7 yang artinya kerusakan terjadi agak tinggi, misalnya kerusakan pada jeruji rotor dan gagal koneksi, yang biasanya disebabkan oleh kotoran dan minyak serta perawatan tidak tepat. untuk nilai detection 10 yang artinya tidak ada alat pengontrol yang mampu mendeteksi, misalnya komponen bearing mengalami kerusakan pada saat proses produksi sedang berlangsung, sehingga satu-satunya cara yang dapat dilakukan yaitu menghentikan sementara proses produksi, kemudian barulah komponen bearing diperiksa untuk melihat seberapa tinggi tingkat kerusakannya.

Tabel 3. Rekapitulasi nilai RPN mesin Cake Breaker Conveyor (CBC)

\begin{tabular}{|c|c|c|c|c|c|c|}
\hline No & Komponen Rusak & Ranking & S & O & D & Nilai RPN \\
\hline 1 & Bearing & 1 & 8 & 7 & 10 & 560 \\
\hline 2 & Batang Kopling & 2 & 8 & 8 & 8 & 512 \\
\hline 3 & Universal Joint & 3 & 8 & 7 & 9 & 504 \\
\hline 4 & Pen & 4 & 8 & 8 & 7 & 448 \\
\hline 5 & As & 5 & 8 & 7 & 6 & 336 \\
\hline 6 & Pedal & 6 & 7 & 6 & 4 & 168 \\
\hline 7 & Gear & 7 & 7 & 4 & 5 & 140 \\
\hline 8 & Shaft & 8 & 8 & 5 & 3 & 120 \\
\hline 9 & Pipa & 9 & 7 & 3 & 3 & 63 \\
\hline 10 & Rotor & 10 & 6 & 5 & 2 & 60 \\
\hline 11 & Stator & 11 & 8 & 7 & 1 & 56 \\
\hline & \multicolumn{7}{|c|}{ Total } & \\
\hline
\end{tabular}

Batang kopling dengan nilai RPN 512, angka tersebut didapat dari nilai severity 8 , dimana nilai 8 tersebut artinya berada pada tingkat sangat tinggi, karena dapat menyebabkan gangguan pada lini produksi, sama halnya kerusakan pada bearing hal tersebut dapat menganggu jalannya proses produksi, 100\% produk harus dibongkar, produk tidak dapat dioperasikan dan kehilangan fungsi utamanya yaitu menghubungkan antara dua poros pada kedua ujungnya, dan untuk nilai occurance sebesar 8, yang artinya kerusakan terjadi tinggi, untuk nilai detection 8 yang artinya alat pegontrol saat ini sangat susah mendeteksi bentuk dan penyebab kegagalan.

Universal Joint dengan nilai RPN 504, angka tersebut didapat dari nilai severity 8 , dimana nilai 8 tersebut artinya berada pada tingkat sangat tinggi, karena dapat menyebabkan gangguan pada lini produksi, $100 \%$ produk harus dibongkar, produk tidak dapat dioperasikan dan kehilangan fungsi utamanya yaitu untuk memungkinkan drive shaft untuk memindahkan atau mentransmisikan daya dan untuk nilai occurance sebesar 7, yang artinya kerusakan terjadi agak tinggi, untuk nilai detection 9 yang artinya alat pengontrol saat ini sangat sulit untuk mendeteksi bentuk dan penyebab kegagalan.

Komponen selanjutnya dengan nilai RPN tertinggi yaitu Pen dengan nilai RPN 448, nilai severity 8 , dimana nilai 8 tersebut artinya berada pada tingkat sangat tinggi, karena dapat menyebabkan gangguan pada lini produksi, sama halnya dengan 3 komponen sebelumnya, 100\% produk harus dibongkar, produk tidak dapat dioperasikan dan kehilangan fungsi utamanya yaitu sebagai penyambungan antara segmen $\mathrm{CBC}$, dan untuk nilai occurance sebesar 8 , yang artinya kerusakan terjadi tinggi, untuk nilai detection 7 yang artinya kemampuan alat pengontrol untuk mendeteksi sangat rendah. Nilai RPN diperoleh dari hasil perkalian antara tingkat keseriusan dari efek yang ditimbulkan (severity), keseringan terjadi kegagalan (occurance) dan Pengendali kegagalan (detection).

\section{Pemilihan tindakan}

Pemilihan tindakan didasari dengan mengelompokkan jenis kerusakan yang terjadi pada mesin Cake Breaker Conveyor kedalam kategori tindakan pencegahan yang sesuai. Gambar 3 merupakan salah satu contoh pemilihan tindakan untuk komponen bearing.

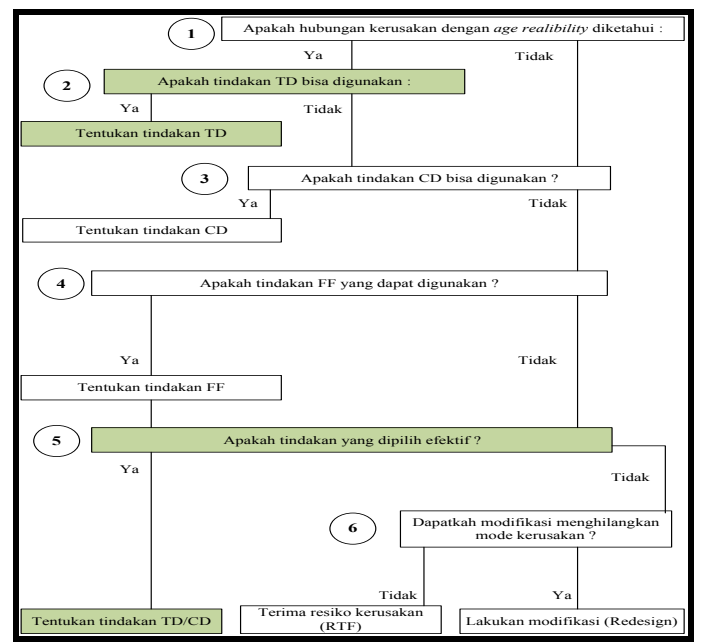

Gambar 3. Pemilihan Tindakan Kerusakan Bearing

Rekapitulasi hasil pemilihan tindakan dapat dilihat pada tabel 4. Untuk komponen bearing pemilihan tindakan perawatan yang terpilih Time Directed (TD) karena tindakan yang dilakukan berupa pencegahan langsung terhadap komponen bearing yang didasarkan pada waktu atau umur komponen. Setelah diperiksa dapat diketahui apakah komponen masih layak digunakan atau tidak, jika tidak maka akan langsung diganti dengan yang baru, namun jika 
masih bisa diperbaiki maka tindakan perbaikan dapat dilakukan

Untuk komponen batang kopling tindakan perawatan yang terpilih adalah condition directed (CD) yaitu tindakan pendeteksian kerusakan pada komponen batang kopling yang mengalami kerusakan seperti komponen Batang Kopling yang pecah/ retak. Tindakan ini dapat dilakukan dengan melihat sekitar bagian sekitaran komponen Batang Kopling, sehingga dapat mencegah kerusakan pada komponen tersebut.

Untuk komponen universal joint pemilihan tindakan perawatan yang terpilih Time Directed (TD) karena tindakan yang dilakukan berupa pencegahan langsung terhadap komponen universal joint yang didasarkan pada waktu atau umur komponen, sama halnya seperti komponen bearing.

Untuk komponen Pen yaitu time directed (TD) dimana tindakan yang dilakukan yaitu pencegahan langsung terhadap sumber kerusakan komponen Pen yang didasarkan pada waktu atau umur komponen. Penindakan ini dilakukan agar tidak terjadinya kerusakan pada komponen mesin yang lain dan tidak mengganggu jalannya proses produksi. proses deteksi dilakukan dengan melihat, mengukur dan mendengar kondisi komponen pada saat ataupun sebelum proses produksi berlangsung, seperti adakah baut yang longgar, goyang atau terdengar bunyi yang tidak biasa, sehingga hal ini dapat menyebabkan terhentinya mesin dan menghambat proses produksi.

Tabel 4. Rekapitulasi Pemilihan Tindakan Perawatan Mesin Cake Breaker Conveyor

\begin{tabular}{|c|c|c|c|}
\hline No & Parts & Failure Mode & $\begin{array}{c}\text { Selection } \\
\text { Task }\end{array}$ \\
\hline 1 & Bearing & Bearing rusak & T.D \\
\hline 2 & Batang Kopling & Kopling pecah/retak & C.D \\
\hline 3 & Universal Joint & Universal joint patah & T.D \\
\hline 4 & Pen & Baut pen cbc putus & T.D \\
\hline
\end{tabular}

\section{Interval Waktu Perawatan Komponen Kritis}

Perhitungan interval waktu penggantian komponen kritis mesin ini menggunakan nilai kehandalan (reliability) mesin. Adapun tujuan melakukan perhitungan nilai kehandalan mesin ini yaitu untuk mengetahui umur optimal dimana tindakan pencegahan seperti pergantian komponen mesin harus dilakukan sehingga dapat mengurangi terjadinya kerusakan secara tiba-tiba yang dapat mengganggu jalannya proses produksi. Rekapitulasi dapat dilihat pada tabel 4.
Berdasarkan pengolahan data bahwa nilai MTTF yaitu sebesar 461,56 jam. Dimana rata-rata umur komponen bearing akan rusak pertama kali sekitar 461,56 jam, dan jika dikaitkan dengan pemilihan tindakan, maka artinya untuk komponen bearing setiap 461,56 jam harus dilakukan Time Directed (TD) berupa pencegahan langsung terhadap komponen bearing yang didasarkan pada waktu atau umur komponen. Setelah diperiksa dapat diketahui apakah komponen masih layak digunakan atau tidak, jika tidak maka akan langsung diganti dengan yang baru, namun jika masih bisa diperbaiki maka tindakan perbaikan dapat dilakukan, dengan kehandalan komponen mesin sebesar 64,64\%. Nilai reliability atau kehandalan dipengaruhi oleh waktu yang artinya semakin lama dan panjangnya waktu penggunaan komponen tersebut maka nilai kehandalannya akan semakin menurun. Maka tindakan yang dilakukan setelah umur komponen 461,56 jam harus dilakukannya perbaikan dan penggantian komponen bearing.

Berdasarkan pengolahan data bahwa nilai MTTF yaitu sebesar 587,29 jam. Dimana rata-rata umur komponen Pen akan rusak pertama kali sekitar 587,29 jam dengan kehandalan komponen mesin sebesar 47,69 \%. Nilai reliability atau kehandalan dipengaruhi oleh waktu yang artinya semakin lama dan panjangnya waktu penggunaan komponen tersebut maka nilai kehandalannya akan semakin menurun. Maka tindakan yang dilakukan setelah umur komponen 581,6 jam harus dilakukannya perbaikan dan penggantian komponen Pen.

Berdasarkan pengolahan data bahwa nilai MTTF yaitu sebesar 536,46 jam. Dimana rata-rata umur komponen Universal Joint akan rusak pertama kali sekitar 536,46 jam dengan kehandalan komponen mesin sebesar 48,99\%. Nilai reliability atau kehandalan dipengaruhi oleh waktu yang artinya semakin lama dan panjangnya waktu penggunaan komponen tersebut maka nilai kehandalannya akan semakin menurun. Maka tindakan yang dilakukan setelah umur komponen 581,6 jam harus dilakukannya perbaikan dan penggantian komponen Universal Joint.

Berdasarkan pengolahan data bahwa nilai MTTF yaitu sebesar 581,6 jam. Dimana ratarata umur komponen Batang Kopling akan rusak pertama kali sekitar 581,6 jam dengan kehandalan komponen mesin sebesar 58,12 \%. Nilai reliability atau kehandalan dipengaruhi oleh waktu yang artinya semakin lama dan panjangnya waktu penggunaan komponen tersebut maka nilai kehandalannya akan semakin menurun. Maka tindakan yang dilakukan setelah umur komponen 
581,6 jam harus dilakukannya perbaikan dan penggantian komponen Batang Kopling.

Tabel IV Rekapitulasi Interval Waktu Perawatan Komponen Kritis

\begin{tabular}{|c|l|c|c|}
\hline No & \multicolumn{1}{|c|}{ Jenis Kerusakan } & Distribusi & $\begin{array}{c}\text { Usulan Jadwal } \\
\text { Pergantian (Jam) }\end{array}$ \\
\hline 1 & Kerusakan Bearing & Lognormal & 461,5 \\
\hline 2 & Kerusakan Pen & Normal & 587,29 \\
\hline 3 & $\begin{array}{l}\text { Kerusakan Universal } \\
\text { Joint }\end{array}$ & Normal & 536,46 \\
\hline 4 & $\begin{array}{l}\text { Kerusakan Batang } \\
\text { Kopling }\end{array}$ & Normal & 581,6 \\
\hline 5 & Kerusakan As & Normal & 586,6 \\
\hline
\end{tabular}

\section{KESIMPULAN}

Jadwal perawatan komponen kritis pada stasiun pemisah biji sebagai berikut: Kerusakan Bearing, distribusi Lognormal, Usulan Jadwal Pergantian 461,5 (Jam), Kerusakan Pen, distribusi Normal, Usulan Jadwal Pergantian 587,29 (Jam), Kerusakan Universal Joint, distribusi Normal, Usulan Jadwal Pergantian 536,46 (Jam), Kerusakan Batang Kopling, distribusi Normal, Usulan Jadwal Pergantian 581,6 (Jam), Kerusakan As distribusi Normal, Usulan Jadwal Pergantian 586,6 (Jam).

Rekomendasi jenis tindakan/aktivitas perawatan yang dilakukan pada setiap komponen kritis yang diteliti.

a. Pemilihan tindakan perawatan yang dilakukan pada kerusakan komponen Bearing terpilih tindakan Time Directed (TD) yaitu dengan mengganti bearing secara langsung berdasarkan umur komponen.

b. Pemilihan tindakan yang dilakukan terhadap komponen Batang Kopling adalah condition directed (CD) yaitu tindakan pendeteksian kerusakan pada komponen Batang Kopling yang mengalami kerusakan seperti komponen Batang Kopling yang pecah/ retak. Tindakan ini dapat dilakukan dengan melihat sekitar bagian sekitaran komponen Batang Kopling.

c. Pemilihan tindakan terhadap komponen Universal Joint yaitu time directed (TD) dimana tindakan yang dilakukan yaitu pencegahan langsung terhadap sumber kerusakan komponen Universal Joint yang yaitu dengan mengganti Universal Joint secara langsung berdasarkan umur komponen. Penindakan ini dilakukan agar tidak terjadinya kerusakan pada komponen mesin yang lain dan tidak mengganggu jalannya proses produksi. d. Pemilihan tindakan terhadap komponen Pen yaitu time directed (TD) dimana tindakan yang dilakukan yaitu pencegahan langsung terhadap sumber kerusakan komponen Pen yaitu dengan mengganti Pen secara langsung berdasarkan umur komponen. Penindakan ini dilakukan agar tidak terjadinya kerusakan pada komponen mesin yang lain dan tidak mengganggu jalannya proses produksi.

\section{Daftar Pustaka}

Atmaji Dwi Tatas, F. (2015), “Optimasi Jadwal Perawatan Pencegahan Pada Mesin Tenun Unit Satu di PT. KSM Yogyakarta.

Aputra, I, Dkk. (2019), "Perencanaan Perawatan Mesin Kompressor pada PT. Es Muda Perkasa dengan Metode Reliability Centered Maintannace (RCM)", Universitas Serambi Mekah.

Azis, Suprawhardana, dan Pudji, Teguh. (2009), "Penerapan Metode Reliability Centered Maintenance (Rcm) Berbasis Web Pada Sistem Pendingin Primer Di Reaktor Serba Guna Ga. Siwabessy", Yogyakarta.

Denur, Dkk. (2018), “Aplikasi Reliability Centered Maintance (RCM) pada Sistem Saluran Gas Mesin Wartsila”, Universitas Muhammadiyah Riau.

Ginting, Rosnani. (2007), Sistem Produksi. Edisi Pertama., Graha Ilmu, Yogyakarta.

Sandriyana Nedi, A, dan Wibowo Joko, T. (2015), "Perencanaan Perawatan Mesin dengan Metode Reliability Centered Maintanance di PT. X”, Jurusan Teknik Industri, Fakultas Teknik. Banten.

Sari Puspita, D, dan Ridho Faizal, M. (2016), "Evaluasi Manajemen Perawatan dengan Reliability Centered Maintenance (RCM) II pada Mesin Blowing I di Plant I PT. Pisma Putra Textile", Universitas Diponegoro.

Sitepu Jaya, W, dan Hermawan, I. (2018), "Tinajuan Perawatan Mesin Mixing pada UD Roti Mawi", Politeknik LP3I Medan.

Suryani, F. (2018), "Penerapan Metode Diagram sebab Akibat (Fishbone Diagram) dan FMEA (Failure Mode and Effect Analysis) dalam Menganalisa Resiko Kecelakaan Kerja di PT. Pertamina Talisman Jambi Merang”, Universitas Tridinanti Palembang. 